\title{
Nicolas Louis François de Neufchâteau, Les Vosges
}

Édition par Philippe Alexandre, avec une notice biographique par JeanPaul Rothiot, Nancy, Fédération des Sociétés savantes des Vosges, 2009, 88 p., ISBN 2-9522166-9-X, $10 €$

\section{Claude Mazauric}

\section{(2) OpenEdition}

\section{Journals}

\section{Édition électronique}

URL : https://journals.openedition.org/ahrf/11813

DOI : $10.4000 /$ ahrf.11813

ISSN : 1952-403X

Éditeur :

Armand Colin, Société des études robespierristes

Édition imprimée

Date de publication : 1 juin 2010

Pagination : 244-245

ISBN : 978-2-200-92632-8

ISSN : 0003-4436

\section{Référence électronique}

Claude Mazauric, "Nicolas Louis François de Neufchâteau, Les Vosges ", Annales historiques de la Révolution française [En ligne], 360 | avril-juin 2010, mis en ligne le 01 juin 2013, consulté le 22 avril 2022. URL : http://journals.openedition.org/ahrf/11813 ; DOI : https://doi.org/10.4000/ahrf.11813

Ce document a été généré automatiquement le 22 avril 2022

Tous droits réservés 


\section{Nicolas Louis François de Neufchâteau, Les Vosges}

Édition par Philippe Alexandre, avec une notice biographique par JeanPaul Rothiot, Nancy, Fédération des Sociétés savantes des Vosges, 2009, 88 p., ISBN 2-9522166-9-X, $10 €$

\section{Claude Mazauric}

\section{RÉFÉRENCE}

Nicolas Louis François de Neufchâteau, Les Vosges, édition par Philippe Alexandre, avec une notice biographique par Jean-Paul Rothiot, Nancy, Fédération des Sociétés savantes des Vosges, 2009, 88 p., ISBN 2-9522166-9-X, $10 €$

François de Neufchâteau est un protagoniste aujourd'hui bien connu de l'invention de la France en révolution et de la construction post-révolutionnaire, notamment grâce à la thèse magistrale de Dominique Margairaz (F. de N. Essai de biographie intellectuelle, Pub. de la Sorbonne, 2005). On savait qu'il avait le goût des lettres et se voulait poète: de découvrir le réel talent qu'il manifestait en ce domaine est un moment insolite et divertissant. Nous voici réunis à Épinal, le $1^{\text {er }}$ vendémiaire an V (22 septembre 1796) à l'occasion de la Fête commémorative de la fondation de la République : le commissaire $\mathrm{du}$ Directoire près de l'administration du département des Vosges qu'est devenu François de Neufchâteau, lit devant le public des notables assemblés, son vaste poème de 600 vers, dédié -c'est ici le mot exact- à la gloire de sa petite patrie : ce pays vosgien et sub-vosgien, devenu « département des Vosges » en 1790, circonscription pour une grande part constituée grâce à l'initiative de François lui-même. Sans doute écrit avant 1795, le poème a été édité à Saint-Dié peu après, tandis qu'une nouvelle édition, augmentée et complétée - dont les ajouts sont reproduits dans la présente réédition de Philippe Alexandre constituée à partir de l'édition princeps d'Épinal - a paru à Paris chez Desenne à l'intention des élites nationales, François étant devenu membre de l'Institut national de France. 
2 François de Neufchâteau est naturellement guidé dans son effort et son inspiration par l'exemple illustre donné par le grand savant bernois Albrecht von Haller (1708-1777) auteur du grand poème Les Alpes (490 vers) paru en 1732, traduit une première fois en français en 1749 , lequel poème contribua à répandre la passion des montagnes dans l'Europe des Lumières: Haller dont la thèse récente (2009) de Florence Catherine montre la grande influence et notoriété dans l'espace cosmopolite où s'est construite la culture d'hommes comme François de Neufchâteau. L'intention fondamentale de l'auteur des Vosges est de donner une sorte d'identité, à la fois « naturelle » et historicoculturelle, voire politique et patriotique, au rassemblement des divers pays de montagnes, de plateaux pré-vosgiens et de vallées, dont l'assemblage a donné naissance au département. Les notes abondantes et précises de Philippe Alexandre, la bibliographie et la référence aux sources, en indiquent précisément la portée et la signification pratique.

3 Reste à lire le poème lui-même. On y trouve des alexandrins de mirliton («Tableaux attendrissants, réguliers et grotesques,/Voilà des deux côtés ce qui frappe mes yeux, / Dans les Alpes, en grand; en petit, dans ces lieux. »), mais aussi de solides évocations inspirées de l'activité manufacturière dont la poésie lyrique rarement fait mention : «À leur chute, plus bas, la scie obéissante, / Divisant comme on veut l'arbre qu'on lui présente [...] Les marteaux de Vulcain, plus loin, retentissants /; Le ductile métal qui passe à la filière [...] Les cendres que le feu métamorphose en verre; / Les vieux chiffons qu'il pile et transforme en papier [...]». Manière de rappeler l'importance industrielle de la Lorraine à la fin du XVIII ${ }^{\text {e }}$ siècle et sa diversité : «Venez voir la nature en ce grand atelier " dont les Vosgiens savent tirer un parti, utile mais aussi esthétique, tout comme ils savent le faire de la pomme de terre («Ce fécond tubercule est la manne des Vosges »), du fromage des Chaumes, ou des eaux de Plombières, Bussang ou Contrexéville, qui contribuent à donner la santé! Évidemment, les Vosges sont loin de Paris : «Dire : comment peut-on vivre à Épinal?» est une question que l'éminent politicien et savant national qu'est devenu François, ne peut pas ne pas se poser (comme bien d'autres après lui... jusqu'au récent défunt Président de la Cour des comptes qui fut un temps député-maire d'Épinal avant de se séparer de cette charge comme d'une guigne!), mais on peut répondre à cette question écologiquement et élégiaquement : « 0 célestes objets, votre charme est suprême ». À quoi s'ajoute le fait heureux que la modernité s'est désormais emparée de tout ce pays avec la République depuis l'élan patriotique depuis 1792 : «Les prêtres ne sont plus; ce n'est pas grand dommage [...] Mais salut aux amis de la philosophie! ». Et puis la beauté est aussi sortie de ces lieux que poètes (Saint Lambert, amant d'Émilie du Châtelet et rival bienheureux de Voltaire), peintres et graveurs (Callot), écrivains et savants, ont parcouru, si près de Nancy, saluée ainsi: "De son plan régulier l'heureuse architecture", pays de montagne, de villes et de vallées qui sont désormais débarrassés d'un mal qualifié ainsi : « Du règne féodal la longue oppression ».

4 «Les progrès du commerce ont servi la raison »: le département des Vosges, une création de la raison pratique? A-t-on souvent entendu un agent de l'État moderne chanter en vers élégants sur un mode kantien, devant ses administrés, la gloire territorialisée d'une politique, d'un régime bourgeois, d'une mutation sociale?

5 François de Neufchâteau n'a pas fini de nous surprendre. 